\title{
Psychometric study of the differentiation of self scale-revised in a sample of Spanish adults
}

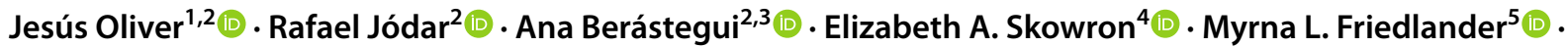 \\ Thomas A. Schmitt ${ }^{6}$
}

Accepted: 15 February 2022

(c) The Author(s) 2022

\begin{abstract}
This study analyzes the psychometric properties of the Differentiation of Self Scale-Revised (DSS-R), an instrument assessing the differentiation of the self of Spanish adults through the dimensions I Position, Emotional Reactivity, Fusion with Others and Emotional Cutoff, and of a new dimension, Dominance over Others. In Study 1, carried out with 1445 subjects, exploratory factor analysis was performed with one half of the participants, and confirmatory factor analysis with the other, comparing the five-factor and bifactor models. In Study 2, examining convergent validity, 180 subjects participated and completed the revised scale and the Differentiation of Self Inventory-Revised. Studies 3 and 4 verified concurrent validity, with 401 subjects completing the DSS-R and the State-Trait Anxiety Inventory in Study 3, and 170 subjects completing the DSS-R and the Couple Assertion Questionnaire in Study 4. Adequate internal consistency indices and evidence of construct, convergent and concurrent validity were found. The use of the DSS-R is recommended for assessing the differentiation of the self in the Spanish population.
\end{abstract}

Keywords Differentiation of self $\cdot$ Scale $\cdot$ Psychometric analysis $\cdot$ Validity $\cdot$ Reliability

Jesús Oliver

jesus.oliver@uma.es

Rafael Jódar

rafajodar@comillas.edu

Ana Berástegui

a.berastegui@comillas.edu

Elizabeth A. Skowron

eskowron@uoregon.edu

Myrna L. Friedlander

mfriedlander@albany.edu

1 Department of Personality, Assessment and Psychological Treatment, University of Málaga, Bulevar Louis Pasteur, 25, CP: 29071 Málaga, Spain

2 Department of Psychology, Comillas Pontifical University, Madrid, Spain

3 Instituto Universitario de la Familia, Comillas Pontifical University, Madrid, Spain

4 Department of Psychology and Center for Translational Neuroscience, University of Oregon, Eugene, OR, USA

5 School of Education, University at Albany, Albany, NY, USA

6 Milwaukee, USA
Family systems theory, proposed by Murray Bowen (1989; Kerr \& Bowen, 1988), is considered one of the most relevant explanations of psychological development from a systemic and multigenerational perspective (Rodríguez \& Kerr, 2011). The theory comprises eight concepts, of which the differentiation of self (DoS) is the most relevant in the field of family therapy, systemic theory and research since it is a fundamental construct for developing maturity and achieving psychological health (Rodríguez-González \& Martínez, 2015).

DoS refers to the intrapsychic ability to distinguish emotional processes from cognitive processes, and to the interpersonal ability to maintain meaningful connections with others while functioning autonomously (Kerr \& Bowen, 1988; Skowron \& Friedlander, 1998).

In the intrapsychic realm, individuals who are more differentiated are better able to distinguish their thoughts from their emotions, making them less emotionally reactive and better able to think clearly in stressful situations and to develop a clear sense of themselves. Conversely, less differentiated people tend to confuse cognitive processes with emotional ones, leading to greater difficulties in regulating emotions, acting reflectively in stressful situations and 
having a clearly defined sense of oneself (Bowen, 1989; Kerr \& Bowen, 1988). According to Skowron and Friedlander (1998), DoS comprises two dimensions at the intrapsychic level: I position and emotional reactivity. I position refers to the clearly defined sense of self and the ability to rationally adhere to one's own convictions even under pressure from others to think or act differently. Emotional reactivity is the tendency to respond to environmental stimuli with automatic emotional responses, flooding, or emotional lability.

In the interpersonal sphere, the most differentiated individuals are better equipped to follow their own criteria, respect the criteria of others and maintain meaningful relationships with others. Less differentiated people, on the other hand, tend to merge with others, to distance themselves physically or emotionally from them or to be dominant (Bowen, 1989; Kerr \& Bowen, 1988). According to Skowron and Friedlander (1998), DoS comprises two dimensions at the interpersonal level: fusion with others and emotional cutoff. Fusion with others can be defined as the reliance or dependence on others, the propensity to think, feel and act like others, the constant need for approval and the weak adherence to one's own criteria in avoiding conflicts or disagreements; while emotional cutoff refers to the tendency to avoid intimacy and keep a physical or emotional distance from others.

Oliver and Berástegui (2019) stated that, at the interpersonal level, there was another expression of a low level of DoS: dominance over others. This new dimension, identified in Bowen's family systems theory (1989), refers to the tendency to adopt dogmatic positions, to tolerate differences of opinion poorly and to pressure others emotionally to conform to the own interests. Kerr and Bowen (1988) point out that "The less well developed each person's individuality, the more easily threatened each can be by "going along" with the other... Each person is attempting to control how the other thinks and acts, each is simultaneously fighting against the other's attempts to control or influence him" (pp. 82-83). Along the same lines, The Bowen Center (2021) postulates that "People with a poorly differentiated "self" depend so heavily on the acceptance and approval of others that they either quickly adjust what they think, say, and do to please others or they dogmatically proclaim what others should be like and pressure them to conform. Bullies depend on approval and acceptance as much as chameleons, but bullies push others to agree with them instead of with others". On the other hand, according to Kerr and Bowen (1988), a person with a high level of differentiation, "While always sure of his beliefs and convictions, he is not dogmatic or fixed in his thinking. He can listen without reacting and can communicate without antagonizing others... He can respect the identity of another without becoming critical or emotionally involved in trying to modify the line course of another... Tolerant and respectful of differences, he is not prone to engage in polarize debates" (p. 107). As noted, all these cites state that people with low differentiation could be dominant while people with high differentiation do not need to display dominant behaviours. Nevertheless, these features were not included or assessed in fusion with others and emotional cutoff dimensions in previous questionnaires, so, people with undifferentiated but dominant interpersonal strategies could have been assessed as well differentiated people. The consideration of this fifth dimension proposed by Oliver and Berástegui (2019) can also help to explain aggressive, dogmatic or violent behaviors from a DoS perspective.

Bowen argued that the level of each person's DoS develops during childhood, consolidates in adolescence and remains relatively stable for the remaining lifespan, although some later life experiences or a structured effort to increase it can generate changes in DoS level (Kerr \& Bowen, 1988). Likewise, Bowen posited that the degree of DoS achieved by a person is strongly related to the level of their own parents' DoS. Through a process that the author labelled "family projection", parents transmit to their children their level of anxiety, their ability to distinguish the emotional from the intellectual system, their ability to relate without losing their autonomy and, ultimately, their level of DoS (Oliver et al., 2012; Peiró et al., 2015). As parents tend to project more on some children than on others, there are usually differences between children in terms of their DoS levels (Bowen, 1989; Rodríguez-González \& Martínez, 2015). Finally, Bowen hypothesized that the level of DoS a person achieves is linked to their physical health, their level of psychological adjustment, and the quality of their relationships at partner, family, and social levels (Kerr \& Bowen, 1988).

Numerous studies have confirmed that individuals with greater DoS suffer less anxiety and other psychological and physical symptoms and enjoy greater psychological wellbeing (e.g., Duch-Ceballos et al., 2020; Isik \& Bulduk, 2015; Jankowski et al., 2013; Rodríguez-González et al., 2018; Sandage \& Jankowski, 2010; Skowron et al., 2009). In addition, more differentiated people seem to have better emotional self-regulation, higher self-esteem and greater identity development, better social skills and more secure adult attachments (e.g., Borondo \& Oliver, 2021; Cavaiola et al., 2012; Duch-Ceballos et al., 2020; Rodrigues, 2016; Willis \& Cashwell, 2017). Finally, individuals with higher levels of DoS have been found to have parents who were more responsive and less critical and absent, have a healthier perception of family functioning and greater adjustment and satisfaction with their partners (e.g., Dolz-del-Castellar \& Oliver, 2021; Freeman \& Almond, 2009; Jankowski \& Hooper, 2012; Kim et al., 2015; Lampis et al., 2019; Rodríguez-González et al., 2020; Skowron, 2000).

In recent decades, a number of instruments have been developed to assess DoS in adults (e.g., PAFS-Q, Bray et al., 1984; LDSS, Haber, 1984; DSI, Skowron \& Friedlander, 
1998), with the Differentiation of Self Inventory-Revised (DSI-R; Skowron \& Schmitt, 2003) currently the most widely used. This instrument assesses DoS through four dimensions: I Position, Emotional Reactivity, Fusion with Others, and Emotional Cutoff.

Since this scale was created, numerous translations of the DSI-R have been made, including Turkish, Chinese, Italian, German, Portuguese and Greek, among other languages (e.g., Isik \& Bulduk, 2015; Lam \& Chan-So, 2015; Lampis et al., 2017; Maß et al., 2019; Major et al., 2014; Neophytou et al., 2020). Recently, the DSI-R scale was adapted to Spanish (S-DSI; Rodríguez-González et al., 2015), with factor analysis revealing a two-factor structure which largely correspond to the Emotional Reactivity and Emotional Cutoff subscales of the DSI-R. Conversely, two fundamental manifestations of DoS did not emerge: I Position and Fusion with Others.

The scales developed so far have contributed significantly to the assessment of DoS. However, some have ignored its intrapsychic components, others its interpersonal components, and several of those examining both components have had issues with construct validity (Licht \& Chabot, 2006; Miller et al., 2004; Skowron \& Schmitt, 2003). On the other hand, as noted, the only scale adapted to Spanish that evaluated DoS did not incorporate some of the fundamental dimensions of the construct. Finally, none of the instruments mentioned above has assessed dominance over others, an interpersonal manifestation of low DoS (Kerr \& Bowen, 1988; Oliver \& Berástegui, 2019).

With the aim of enabling an assessment of DoS and its intrapsychic and interpersonal components in the Spanish population, including dominance over others, Oliver and Berástegui (2019) created the Differentiation of Self Scale (DSS; in Spanish, Escala de Diferenciación del Self, EDS). This instrument consists of 74 items, 28 of which were translated from the DSI-R scale (Skowron \& Schmitt, 2003), and assesses five dimensions of DoS: I Position, Emotional Reactivity, Fusion with Others, Dominance over Others and Emotional Cutoff. The scale showed adequate psychometric properties (internal consistency indices, construct validity, criterion validity) and has been used in several subsequent studies (e.g., Borondo \& Oliver, 2021; Dolz-del-Castellar \& Oliver, 2021; Duch-Ceballos et al., 2020; Oliver, 2020). However, the initial scale construction study (Oliver \& Berástegui, 2019) involved only a small number of participants, and no other validated instruments were used to examine convergent and concurrent validity. In addition, the instrument has 74 items, which makes its application difficult and may contribute to participant fatigue.

The objective of this study was thus to analyze the psychometric characteristics of the Differentiation of Self Scale by applying the instrument to a larger and more representative number of participants and analyzing its relationship with other instruments for evaluating DoS and other theoretically related variables: trait anxiety and couple assertiveness. In addition, a reduction in the number of scale items was attempted in order to facilitate its application. Finally, the essential unidimensionality and multidimensionality of the scale would be explored with 5 -factor and bifactor CFA. Bifactor models showed central advantages over second-order models (Chen et al., 2012; Rodriguez et al., 2016) and will be computed in Study 1 . The instrument is intended to be used to evaluate Bowen's original construct in a more accurate way, and enable examination of adult functioning and treatment outcomes from a systemic perspective.

Four studies were carried out to analyze the psychometric properties of the Differentiation of Self Scale. Study 1 examined the factorial structure of the original scale. The number of items was reduced and the construct validity of the resulting scale was verified. In Study 2, the convergent validity of the new scale was examined, and Studies 3 and 4 verified its concurrent validity by analyzing its relationship with trait anxiety and couple assertiveness.

\section{Study 1. Exploratory and Confirmatory Analysis}

This study aimed to analyze the factorial structure of the Differentiation of Self Scale, reduce the number of items and examine the construct validity of the scale.

\section{Method}

\section{Participants}

Convenience and snowball sampling was used to recruit participants. In order to carry out an exploratory and confirmatory factor analysis, Nunally (1978), Thorndike (1982), and Bentler and Chou (1987) recommended to use a sample of 10 times larger than the number of the items of the scale, so an attempt was made to get a larger enough sample to meet this requirement. Inclusion criteria were being over 18 years of age and of Spanish nationality. A total of 1445 adults from various regions in Spain took part in the study, with 901 women (62.4\%) and 544 men (37.4\%). Ages ranged from 18 to 86 years, with a mean of 35.9 years $(S D=14.2)$. In terms of academic achievement, $74.6 \%$ of the participants had university education, $12.3 \%$ had been high school, $9.0 \%$ had vocational training, 2.2\% had lower secondary and $1.9 \%$ had primary schooling.

Using SPSS procedure for creating random samples of approximately $50 \%$ of cases, the participants were divided into two groups to perform exploratory factor analysis with the first group and confirmatory factor analysis with the second. Group 1 comprised 697 subjects and Group 2 had 748 subjects. 


\section{Instruments}

Differentiation of Self Scale (DSS; in Spanish, Escala de Diferenciación del Self, EDS) This scale, designed by Oliver and Berástegui (2019), assesses the intrapsychic and interpersonal dimensions of DoS in adults. It consists of 74 items, with 6 response options (from 1 Disagree completely to 6 Agree completely) and five subscales: I Position (IP), with 13 items, refers to a clearly defined sense of oneself, the ability to set goals for oneself, distinguish one's own thoughts and feelings from those of others, and rationally adhere to one's own convictions even in stressful situations. The 12-item Emotional Reactivity (ER) scale explores the tendency to respond to environmental stimuli in an uncontrolled, labile manner and with autonomous emotional responses. Fusion with Others (FO), with 14 items, refers to the tendency to think, feel and act like others, disregarding one's own criteria in order to avoid conflicts and disagreements and seek approval. The 21-item Emotional Cutoff (EC) scale reflects the tendency to avoid intimacy by physically or emotionally distancing oneself from others. Finally, Dominance over Others (DO), with 14 items, explores the tendency to put pressure on others to conform to one's own interests, to tolerate differences of opinion poorly, to enter into power struggles with others and to be dogmatic.

Each subscale is computed by summing item scores and dividing the result by the number of items in the subscale. Scores on each subscale thus range from 1 to 6 , with higher scores reflecting a greater level in that dimension. On the other hand, because IP is directly related to DoS and the other four subscales are inversely related to DoS, to compute the DSS-full scale score, the IP score and the reversed ER, FO, DO, and EC scores must be summed (IP + (7-ER) + (7FO) $+(7-D O)+(7-E C))$, and the result must be divided by 5 . Scores on DSS-full scale score thus range from 1 to 6 , with higher scores reflecting a greater level of differentiation. The internal consistency indices (Cronbach's alpha) of the scale and its subscales were high: $\mathrm{DSS}=.93, \mathrm{IP}=.86, \mathrm{ER}=.89$, $\mathrm{FO}=.90, \mathrm{DO}=.89$, and $\mathrm{EC}=.90$.

Regarding evidence of criterion validity, significant associations of DoS and its dimensions with emotional maturity, normal anxiety, general well-being and satisfaction with family and peers were found.

\section{Procedure}

The study was of a cross-sectional correlational quantitative type. Subjects were recruited by disseminating the research project among psychology students at the Comillas Pontifical University, sociology students at the Rey Juan Carlos University and psychology, speech therapy and advertising and public relations students at the University of Malaga, and through Linkedin among professionals in the psychosocial field. The presentation invited people to participate in the study and to circulate the invitation among their contacts.

Participants were asked to complete an online questionnaire via Google Forms. In the presentation, the aims of the study were explained, a minimum age of 18 years was stipulated, precise instructions were given on how to complete the questionnaire, confidentiality was guaranteed and subjects were thanked for their participation. The present study, as well as the subsequent ones, was approved by the Ethics Committee of the University.

\section{Data Analysis}

First, exploratory factor analysis (EFA) was carried out with Group 1, with a parallel analysis to detect the number of factors to extract, using the robust maximum likelihood method and the Oblimin rotation method (Sass \& Schmitt, 2010; Schmitt, 2011; Schmitt \& Sass, 2011). Second, confirmatory factor analysis (CFA) was performed with Group 2. The fit measures applied were the $\chi 2$ statistic, the chi-square ratio $\left(\chi^{2} / \mathrm{df}\right)$, the comparative fit index (CFI), the Tucker-Lewis index (TLI), the root mean square error of approximation (RMSEA), and the standardized root mean square residual (SRMR). Cut-off criteria were as follows: $\leq 3$ for the $\chi^{2} / \mathrm{df}$ ratio; $\geq 0.90$ for the CFI and TLI; $\leq 0.06$ for the RMSEA, and $<0.8$ for the SRMR (Bentler, 1990; Bentler \& Bonett, 1980; Brown, 2015).

The internal consistency of the revised scale and its subscales was then calculated using Cronbach's alpha, McDonald's omega, hierarchical omega and explained common variance (ECV). The highest hierarchical omega and ECV reflect greater factorial one-dimensionality in bifactor models (Tang et al., 2014). Hierarchical omega and ECV > .80 were considered indicators of one-dimensionality. Several Pearson correlations were performed to examine the relationship between the revised scale and its subscales. SPSS v.26 was used to calculate the correlations and perform the parallel analysis. R (R Core Team, 2020), with the "psych" package (Revelle, 2019), and "BifactorIndicesCalculator" package (Dueber, 2021), were used for calculating reliability, and Mplus 6 to perform factor analysis (Muthén \& Muthén, 1998-2017).

\section{Results}

First, with Group 1, the parallel analysis showed the suitability of selecting five factors. At each step, saturation criteria were applied (great than .40 for its factor and less than .30 for the rest), Cronbach's alpha was calculated (based on item deletion), and parallel analysis was computed at each step. The saturations of the 25 items that were finally retained, 
of which 7 were translated from the DSI-R (Skowron \& Schmitt, 2003), are shown in Table 1.

When analyzing the content of the factors, it was concluded that Factor 1 (5 items) was associated with Dominance over Others (DO), that is, with the tendency to pressure others to conform to their own interests, to tolerate differences of opinion poorly, to enter into power struggles with others and to be dogmatic. Factor 2 (5 items) was related to the I Position (IP), that is, with a clearly defined sense of oneself, the ability to set goals for oneself, distinguish one's own thoughts and feelings from those of others, and rationally adhere to one's own convictions even in stressful situations. Factor 3 (5 items) was related to Emotional Reactivity (ER), that is, the tendency to respond to environmental stimuli in an uncontrolled, labile way and with autonomous emotional responses. Factor 4 (6 items) was related to Emotional Cutoff (EC), that is, to avoiding intimacy through physical or emotional distance from others. Finally, Factor 5 (4 items) was associated with Fusion with Others (FO), that is, with the tendency to think, feel and act like others, disregarding one's own criteria in order to avoid conflicts and disagreements and seek approval. ER, FO, DO and EC have an inverse relationship with the construct, that is, the higher the score on these factors, the lower the DoS. IP has a direct relationship with the construct, that is, the higher the score on this factor, the higher the DoS.

In relation to the internal consistency indices, the revised Differentiation of Self Scale and its subscales obtained high Cronbach's alpha $(\mathrm{DSS}-\mathrm{R}=.91, \mathrm{IP}=.90, \mathrm{ER}=.85, \mathrm{FO}=.85$, $\mathrm{DO}=.85$, and $\mathrm{EC}=.81)$ and McDonald's omega values $(\mathrm{DSS}-\mathrm{R}=.92, \mathrm{IP}=.90, \mathrm{ER}=.86, \mathrm{FO}=.85, \mathrm{DO}=.85$, and $\mathrm{EC}=.81)$.

Next, Group 2 was subject to a confirmatory factor analysis of the revised Differentiation of Self Scale, comprising 25 items and five subscales: I Position (IP), Emotional Reactivity (ER), Fusion with Others (FO), Dominance over Others (DO) and Emotional Cutoff (EC).

The five-factor model had a sufficient fit $\left(\chi^{2}(265)=1014.3, p<.001, C F I=.91, T L I=.89\right.$, $R M S E A=.06, S R M R=.07)$. A bifactor model, with a general factor (differentiation of self) and five independent domain specific factors (IP, ER, FO, DO and EC), also was

Table 1 Items of the Differentiation of Self Scale and Factor Loadings (Rotation method: Oblimin)

\begin{tabular}{|c|c|c|c|c|c|}
\hline \multirow[b]{2}{*}{ Items } & \multicolumn{5}{|c|}{ Factors } \\
\hline & DO & IP & ER & $\mathrm{EC}$ & FO \\
\hline 29. Tiendo a presionar a los demás para pensar y hacer las cosas a mi manera & .84 & -.07 & -.09 & .04 & .03 \\
\hline 16. Suelo tratar de imponer mis ideas y mis deseos a los demás & 69 & .13 & -.03 & -.02 & .06 \\
\hline 32. Me gusta salirme siempre con la mía & .69 & -.16 & .02 & -.01 & -.08 \\
\hline 41. Me molesto cuando los demás no piensan como yo & .60 & .10 & .13 & .08 & .04 \\
\hline 7. Tiendo a hacer que mis padres/parejas hagan lo que yo quiero & .53 & .23 & -.01 & .05 & .03 \\
\hline 49. Tengo un conjunto de valores y creencias bien definido & .02 & .80 & -.05 & .13 & -.04 \\
\hline 48. Puedo juzgar por mí mismo/a si hago o no hago bien las cosas & .06 & .79 & .01 & .03 & -.03 \\
\hline 2. Tiendo a permanecer fiel a mis ideas incluso en situaciones de tensión & -.04 & .71 & -.07 & -.03 & .14 \\
\hline 68. Tengo claro quién soy, lo que creo, lo que defiendo, y lo que haré o no haré & .00 & .69 & .04 & .15 & .07 \\
\hline 47. Distingo con facilidad mis pensamientos y sentimientos de los pensamientos y sentimientos de los demás & .02 & .69 & .07 & .06 & -.01 \\
\hline 71. A menudo sufro altibajos emocionales & -.05 & .04 & .76 & .12 & -.05 \\
\hline 21. A veces me siento como si estuviera en una montaña rusa emocional & -.01 & .05 & .76 & .18 & -.10 \\
\hline 61. Me afectan las cosas de forma mucho más intensa que a los demás & -.05 & .13 & .74 & -.08 & .08 \\
\hline 12. En ocasiones, mis sentimientos me desbordan y no me dejan pensar con claridad & -.06 & -.07 & .72 & .05 & .08 \\
\hline 40. Se me hiere con mucha facilidad & .16 & -.13 & .60 & -.08 & .11 \\
\hline 72. La gente a la que quiero no conoce mis verdaderos pensamientos ni sentimientos sobre algunas cosas & -.04 & -.15 & .14 & .60 & .14 \\
\hline 6. A menudo me siento inhibido cuando estoy con mi familia & .05 & .17 & .05 & .58 & .05 \\
\hline 31. Cuando estoy con mi familia o con mi pareja, a menudo me siento reprimido & .20 & .08 & .06 & .56 & .10 \\
\hline 74. Evito contarle a la gente mis problemas & -.08 & -.17 & -.01 & .53 & .19 \\
\hline 28. Siempre evitaré recurrir a alguien de mi familia en busca de apoyo emocional & .13 & .16 & .00 & .52 & .05 \\
\hline 50. Siento como si entre mis familiares y yo se hubiera roto el vínculo & .17 & .29 & 0.09 & .50 & -.02 \\
\hline 19. Con frecuencia, me muestro de acuerdo con los demás para evitar disgustarles & .03 & -.03 & .03 & .04 & .79 \\
\hline 54. En ocasiones, cambio mis opiniones para evitar discusiones con los demás & -.02 & .12 & -.05 & .06 & .67 \\
\hline 64. Tiendo a evitar discrepar, para que los demás no se molesten & .00 & .06 & .04 & .08 & .66 \\
\hline 36. Mis decisiones se ven influidas fácilmente por la presión de los demás & .17 & .21 & .12 & .02 & .43 \\
\hline
\end{tabular}

$D O$ Dominance over Others; IP I Position; ER Emotional Reactivity; EC Emotional Cutoff; FO Fusion with Others 
tested and it had an acceptable fit $\left(\chi^{2}(250)=815.7, p<.001\right.$, $C F I=.93, T L I=.91, R M S E A=.06, S R M R=.05)$. As shown in Table 2, all parameters were statistically significant.

Confirmatory factor analysis thus indicated that the 25-item Differentiation of Self Scale-Revised (DSS-R) consists of five factors or subscales (see Annexes 1 and 2). I Position, Emotional Reactivity, Fusion with Others and Emotional Cutoff are similar to the subscales of the Differentiation of Self Inventory-Revised (Skowron \& Schmitt, 2003) and the Spanish Differentiation of Self Inventory (Rodríguez-González et al., 2015). Moreover, the scale incorporates Dominance over Others. While IP is directly related to the construct, that is, the higher the score, the higher the level of DoS, the other subscales are inversely related with the construct, with the higher the ER, FO, DO and EC score, the lower the level of DoS.

Table 3 shows the relationships between the DSS-R and its subscales. The magnitude of the strong relationships between the DSS-R and IP, ER, FO, DO and DO stands out. Similarly, the strong negative relationship of IP with
FO and EC, and the strong positive relationship between FO and EC should be noted.

As regards internal consistency indices with this group, the DSS-R scale and its subscales obtained high Cronbach's alpha (DSS-R $=.91, \mathrm{IP}=.89, \mathrm{ER}=.85, \mathrm{FO}=.83$, $\mathrm{DO}=.82$, and $\mathrm{EC}=.83)$ and McDonald's omega values $(\mathrm{DSS}-\mathrm{R}=.91, \mathrm{IP}=.89, \mathrm{ER}=.85, \mathrm{FO}=.83, \mathrm{DO}=.83$, and $\mathrm{EC}=.83$ ). The hierarchical omega was .76 , and $\mathrm{ECV}=.47$, neither of them reaching the cut-off point of .80 to consider the one-dimensionality of the scale.

As the majority of the sample had university education, it was analyzed if there were differences between participants with university education and with no-university education in DoS. Small differences were found in $\operatorname{DoS}(t(657)=-3.20, p=.001$, Cohen's $d=.28)$, ER $(t(657)=2.27, p=.024$, Cohen's $d=.20)$ and EC $(t(657)=4.92, p=<.001$, Cohen's $d=.43)$, with higher levels of differentiation and lower levels of ER and EC in participants with university education.
Table 2 Completely

standardized factor loadings of bifactor model

\begin{tabular}{|c|c|c|c|c|c|c|}
\hline Item & General factor & IP & ER & $\mathrm{EC}$ & FO & DO \\
\hline D2 & $0.63(0.04)$ & $0.33(0.07)$ & & & & \\
\hline D47 & $0.63(0.05)$ & $0.39(0.08)$ & & & & \\
\hline D48 & $0.69(0.04)$ & $0.42(0.07)$ & & & & \\
\hline D49 & $0.74(0.03)$ & $0.50(0.05)$ & & & & \\
\hline D68 & $0.73(0.04)$ & $0.42(0.07)$ & & & & \\
\hline D12 & $0.30(0.04)$ & & $0.64(0.03)$ & & & \\
\hline D21 & $0.38(0.04)$ & & $0.74(0.03)$ & & & \\
\hline D40 & $0.22(0.04)$ & & $0.56(0.04)$ & & & \\
\hline D61 & $0.29(0.04)$ & & $0.70(0.03)$ & & & \\
\hline D71 & $0.39(0.04)$ & & $0.67(0.03)$ & & & \\
\hline D6 & $0.60(0.07)$ & & & $0.30(0.15)$ & & \\
\hline D28 & $0.48(0.07)$ & & & $0.55(0.11)$ & & \\
\hline D31 & $0.67(0.06)$ & & & $0.34(0.10)$ & & \\
\hline D50 & $0.69(0.06)$ & & & $0.31(0.14)$ & & \\
\hline D72 & $0.33(0.04)$ & & & $0.53(0.12)$ & & \\
\hline D74 & $0.17(0.04)$ & & & $0.54(0.14)$ & & \\
\hline D19 & $0.56(0.04)$ & & & & $0.56(0.05)$ & \\
\hline D36 & $0.66(0.04)$ & & & & $0.27(0.06)$ & \\
\hline D54 & $0.58(0.04)$ & & & & $0.57(0.04)$ & \\
\hline D64 & $0.51(0.04)$ & & & & $0.61(0.04)$ & \\
\hline D7 & $0.45(0.04)$ & & & & & $0.54(0.04)$ \\
\hline D16 & $0.43(0.04)$ & & & & & $0.69(0.03)$ \\
\hline D29 & $0.31(0.05)$ & & & & & $0.74(0.03)$ \\
\hline D32 & $0.07(0.05)$ & & & & & $0.71(0.03)$ \\
\hline D41 & $0.52(0.04)$ & & & & & $0.51(0.04)$ \\
\hline
\end{tabular}

Standard errors in brackets. IP I Position; ER Emotional Reactivity; FO Fusion with Others; $D O$ Dominance over Others; EC Emotional Cutoff

All $p$ values for the five factors were $<.001$ 
Table 3 Matrix of intercorrelations between the DSS-R and its subscales

\begin{tabular}{lllllll}
\hline & DSS-R & IP & ER & FO & DO & EC \\
\hline DSS-R & - & & & & & \\
IP & $.77^{*}$ & - & & & \\
ER & $-.62^{*}$ & $-.24^{*}$ & - & & \\
FO & $-.78^{*}$ & $-.62^{*}$ & $.35^{*}$ & - & \\
DO & $-.61^{*}$ & $-.30^{*}$ & $.27^{*}$ & $.25^{*}$ & - & \\
EC & $-.77^{*}$ & $-.54^{*}$ & $.29^{*}$ & $.52^{*}$ & $.37^{*}$ & - \\
\hline
\end{tabular}

Pearson's correlation coefficient. DSS-R Differentiation of Self Scale-Revised; IP I Position; ER Emotional Reactivity; $F O$ Fusion with Others; $D O$ Dominance over Others; EC Emotional Cutoff. Higher scores on DSS-R and its subscales indicate greater differentiation of self, I position, emotional reactivity, fusion with others, emotional cutoff, and dominance over others. Higher scores on IP and lower scores on ER, FO, DO and EC indicate a greater differentiation of self

$* p<.05$

\section{Study 2. Convergent Validity}

This study aimed to examine the correlations between this scale and the DSI-R, to explore the convergent validity of the DSS-R.

\section{Method}

\section{Participants}

Participants were recruited using convenience and snowball sampling. Inclusion criteria were being aged over 18 years and of Spanish nationality. Of the 1445 adults who participated in Study 1, 180 adults also took part in this study. 120 were women $(66.7 \%)$ and 60 were men (33.3\%), aged between 19 and 86 years, with a mean age of 32.1 years $(\mathrm{SD}=11.6)$. In terms of academic achievement, $74.6 \%$ of participants reported having a university education, $13.1 \%$ high school, $6.9 \%$ vocational training, $4.6 \%$ lower secondary and $0.8 \%$ primary education.

\section{Instruments}

Differentiation of Self Scale-Revised (DSS-R; in Spanish, Escala de Diferenciación del Self-Revisada, EDS-R) This scale assesses DoS in adults. It comprises 25 items, with 6 response options (from 1 Completely disagree to $6 \mathrm{Com}$ pletely agree) and five subscales: I Position (IP), Emotional Reactivity (ER), Fusion with Others (FO), Dominance over Others (DO) and Emotional Cutoff (EC). Higher scores on DSS-R and its subscales indicate greater DoS, I position, emotional reactivity, fusion with others, emotional cutoff, and dominance over others. On the other hand, the first subscale is directly related to the construct, that is, the higher the IP, the higher the degree of DoS. The other four subscales are inversely related to the construct, with higher scores reflecting a correspondingly lower degree of DoS.

Each subscale is computed by summing item scores, and then, dividing the result by the number of items in the subscale. Scores on each subscale thus range from 1 to 6 , with higher scores reflecting a greater level in that dimension. On the other hand, because IP is directly related to DoS and the other four subscales are inversely related to DoS, to compute the DSS-full scale score, the IP score and the reversed ER, FO, DO, and EC scores must be summed (IP + (7-ER) + (7$\mathrm{FO})+(7-\mathrm{DO})+(7-\mathrm{EC}))$, and the result must be divided by 5 (see correction norms in Annexes 1 and 2). Scores on DSSfull scale score thus range from 1 to 6 , with higher scores reflecting a greater level of differentiation.

The results of the present study were as follows: Cronbach's alpha DSS-R $=.85, \mathrm{IP}=.70, \mathrm{ER}=.79, \mathrm{FO}=.75$, $\mathrm{DO}=.80$, and $\mathrm{EC}=.72 ;$ McDonald's omega $\mathrm{DSS}-\mathrm{R}=.86$, $\mathrm{IP}=.71, \mathrm{ER}=.80, \mathrm{FO}=.77, \mathrm{DO}=.80$, and $\mathrm{EC}=.72$.

Differentiation of Self Inventory-Revised (DSI-R) This instrument, created by Skowron and Schmitt (2003) and translated for this research, assesses DoS in adults. It consists of 42 items, with 6 response options (from 1 Completely disagree to 6 Completely agree), and four subscales: I Position (IP), Emotional Reactivity (ER), Fusion with Others (FO) and Emotional Cutoff (EC). According to its scoring guidelines, higher scores indicate higher DoS and IP, and lower ER, FO and EC. However, in the present study, items were coded so that higher scores indicate higher levels of DoS, IP, ER, FO and EC. Furthermore, higher scores on IP, and lower scores on ER, FO, DO and EC indicate a greater DoS.

The internal consistency indices (Cronbach's alpha) of the scale and subscales were high: $\mathrm{DSI}-\mathrm{R}=.92, \mathrm{IP}=.81$, $\mathrm{ER}=.89, \mathrm{FO}=.86$ and $\mathrm{EC}=.84$. In the present study, the internal consistency indices were as follows: DSI-R $=.89$, $\mathrm{IP}=.78, \mathrm{ER}=.83, \mathrm{FO}=.81$ and $\mathrm{EC}=.72$. 


\section{Procedure}

The study was of a quantitative cross-sectional correlational type. A presentation of the research and a Google Forms questionnaire were disseminated among psychology students at the Comillas Pontifical University and among sociology students at the Rey Juan Carlos University, both in Madrid, and on Linkedin among professionals in the psychosocial field. In the presentation, interested parties were invited to participate in the study and to circulate the invitation among their contacts.

\section{Data Analysis}

First, the McDonald's omega of the DSS-R and the Cronbach's alpha of the three scales were calculated. After this, several Pearson correlations were carried out to analyse the relationships between the DSS-R and the DSI-R.

\section{Results}

As shown in Table 4, the DSS-R was observed to be positively and highly related to the DSI-R. Similarly, IP was positively and strongly related to IP in the DSI-R. Likewise, the relationship across both instruments was very high and positive for ER, quite high and positive for FO, and very high and positive for EC. In addition, it was observed that DO was related negatively and moderately with DSI-R total score, negatively and highly with IP, in a positive and moderate way with EC, and in a negative and weak way with FO of the DSI-R, indicating that higher scores on DO of the DSS-R were associated with lower scores on DoS, IP and FO and higher scores on EC of the DSI-R.
Study 3. Concurrent Validity with an Intrapsychic Variable: Trait Anxiety

The aim of this study was to examine the concurrent validity of the DSS-R.

\section{Method}

\section{Participants}

Participants were recruited by means of convenience and snowball sampling. Inclusion criteria were being aged over 18 years and of Spanish nationality. Of the 1445 adults who participated in Study 1, 401 adults also took part in this study. 263 were women (65.6\%) and 138 were men (34.4\%). Age ranged from 18 to 71 years, with a mean of 27.3 years $(\mathrm{SD}=12.0)$. In terms of academic achievement, $78.8 \%$ of the participants reported having university education, $15.7 \%$ went to high school, $3.0 \%$ had vocational training, $1.5 \%$ had lower secondary and $1.0 \%$ primary education.

\section{Instruments}

Differentiation of Self Scale-Revised (DSS-R; in Spanish, Escala de Diferenciación del Self-Revisada, EDS-R) Internal consistency indices in the present study were adequate: Cronbach's alpha DSS-R $=.84, \mathrm{IP}=.74, \mathrm{ER}=.87, \mathrm{FO}=.80$, $\mathrm{DO}=.81$, and $\mathrm{EC}=.80 ;$ McDonald's omega $\mathrm{DSS}-\mathrm{R}=.84$, $\mathrm{IP}=.76, \mathrm{ER}=.88, \mathrm{FO}=.80, \mathrm{DO}=.82$, and $\mathrm{EC}=.81$.

State-Trait Anxiety Inventory The State-Trait Anxiety Inventory (STAI), developed by Spielberger et al. (1970), was adapted to Spanish by Seisdedos (1986). This instrument comprises two scales assessing Trait Anxiety (TA) and State Anxiety (SA). Each scale has 20 items with four response options (from 0 Nothing/Almost never to 3 A lot/Almost
Table 4 Matrix of correlations of the Differentiation of Self Scale-Revised (DSS-R) with the Differentiation of Self Inventory-Revised (DSI-R)

\begin{tabular}{lllllll}
\hline & DSS-R & IP & ER & FO & DO & EC \\
\hline DSI-R & $.83^{*}$ & $.61^{*}$ & $-.78^{*}$ & $-.73^{*}$ & $-.28^{*}$ & $-.43^{*}$ \\
IP $_{(\text {DSI-R })}$ & $.71^{*}$ & $.54^{*}$ & $-.46^{*}$ & $-.50^{*}$ & $-.52^{*}$ & $-.38^{*}$ \\
ER $_{(\text {DSI-R })}$ & $-.64^{*}$ & $-.43^{*}$ & $.88^{*}$ & $.58^{*}$ & .09 & $.16^{*}$ \\
FO $_{(\text {DSI-R })}$ & $-.42^{*}$ & $-.46^{*}$ & $.51^{*}$ & $.58^{*}$ & $-.15^{*}$ & .09 \\
EC $_{(\text {DSI-R })}$ & $-.72^{*}$ & $-.38^{*}$ & $.40^{*}$ & $.50^{*}$ & $.44^{*}$ & $.73^{*}$ \\
\hline
\end{tabular}

Pearson's correlation coefficient. DSS-R Differentiation of Self Scale-Revised; DSI-R Differentiation of Self Inventory-Revised. IP I Position; ER Emotional Reactivity; FO Fusion with Others; DO Dominance over Others; EC Emotional Cutoff. Higher scores on DSS-R, DSI-R and its subscales indicate greater differentiation of self, I position, emotional reactivity, fusion with others, emotional cutoff, and dominance over others. Higher scores on IP and lower scores on ER, FO, DO and EC indicate a greater differentiation of self. Higher scores on IP ${ }_{(\text {DSI-R) }}$, and lower scores on ER (DSI-R) $, \mathrm{FO}_{(\text {DSI-R) }}, \mathrm{DO}_{(\mathrm{DSI}-\mathrm{R})}$ and EC $\mathrm{ESSI-R)}_{\text {indi- }}$ cate a greater differentiation of self

$* p<.05$ 
always). The higher the total score on each scale, the higher the level of anxiety.

Internal consistency (Cronbach's alpha) values range from .83 to .92 . In the present study, only the trait anxiety scale was used, because Bowen stated that the average level of chronic anxiety is similar to the level of differentiation of a person. In this sense, people with higher levels of differentiation should have lower levels of trait anxiety because they are more capable to deal with normal stressful situations; however, they could have high levels of state anxiety because they are suffering very stressful situations. In this study, a Cronbach's alpha of .92 was obtained.

\section{Procedure}

The study was of a quantitative cross-sectional correlational type. A presentation of the research and a Google Forms questionnaire were disseminated among psychology students at the Comillas Pontifical University and psychology, speech therapy and advertising and public relations students at the University of Malaga, and on Linkedin among professionals in the psychosocial field. In the presentation, interested parties were invited to participate in the study and to circulate the invitation among their contacts.

\section{Data Analysis}

First, the McDonald's omega of the DSS-R and the Cronbach's alpha of both scales were calculated. After this, several Pearson correlations were performed to examine the relationship of the DSS-R with the STAI Trait-Anxiety subscale.

\section{Results}

Trait-anxiety was found to be highly negatively related to the DSS-R $(r=-.72, p<.001)$ and moderately negatively to IP $(r=-.33, p<.001)$. There was a highly positive relationship with ER $(r=.73, p<.001), \mathrm{FO}(r=.33, p<.001)$ and EC $(r=.45, p<.001)$, and a moderately positive one with DO $(r=.23, p<.001)$, indicating that greater trait anxiety was associated with greater ER, EC, DO and less ability to take an IP in relationships with others.

\section{Study 4. Concurrent Validity with an Interpersonal Variable: Couple Assertion}

The aim of this study was to examine the concurrent validity of the DSS-R.

\section{Method}

\section{Participants}

Convenience and snowball sampling was used to recruit the participants. Inclusion criteria were being aged over 18 years and of Spanish nationality. Of the 1445 adults who participated in Study 1, 170 adults also took part in this study. 109 were women $(64.1 \%)$ and 61 were men $(35.9 \%)$, with an age range from 18 to 73 years, and a mean age of 41.7 years $(S D=13.9)$. A university education was held by $80.6 \%$ of the participants, with $5.3 \%$ having high school, $10.6 \%$ vocational training, $0.6 \%$ secondary and $2.9 \%$ primary education.

\section{Instruments}

Differentiation of Self Scale-Revised (DSS-R; in Spanish, Escala de Diferenciación del Self-Revisada, EDS-R) Internal consistency indices in the present study were adequate: Cronbach's alpha DSS-R $=.87, \mathrm{IP}=.71, \mathrm{ER}=.87, \mathrm{FO}=.81$, $\mathrm{DO}=.82$, and $\mathrm{EC}=.76$; McDonald's omega $\mathrm{DSS}-\mathrm{R}=.87$, $\mathrm{IP}=.73, \mathrm{ER}=.87, \mathrm{FO}=.81, \mathrm{DO}=.83$, and $\mathrm{EC}=.77$.

Couple Assertion Questionnaire (CAQ; in Spanish, Cuestionario de Aserción en la Pareja, ASPA) This questionnaire, constructed by Carrasco (1996), assesses the behaviours associated with assertiveness in adult couples. The questionnaire is made up of two scales: A, evaluating one's own behaviour, and $\mathrm{B}$, to evaluate the behaviour of the other member of the couple. Each scale comprises 40 items, with six response options (from 1 Almost never to 6 Almost always), and four subscales of 10 items each: Assertion, Aggressiveness, Submission and Passive-Aggressiveness.

This study used form A of the instrument, which has adequate internal consistency indices (Cronbach's alpha): Assertion $=.83$, Aggressiveness $=.81$, Submission $=.75$ and Passive-Aggressiveness $=.74$. In the present study, the following internal consistency indices were obtained (Cronbach's alpha): Assertion $=.85$, Aggressiveness $=.89$, Submission $=.87$ and Passive-Aggressiveness $=.88$.

\section{Procedure}

The study was of a quantitative cross-sectional correlational type. A presentation of the research and a Google Forms questionnaire were disseminated among psychology and speech therapy students of the University of Malaga and on Linkedin among professionals in the psychosocial field. In the presentation, interested parties were invited to 
participate in the study and to circulate the invitation among their contacts.

\section{Data Analysis}

After calculating the McDonald's omega of the DSS-R and the Cronbach's alpha of both scales, several Pearson correlations were determined to verify the relationship of the DSS-R with the CAQ.

\section{Results}

As show in Table 5, DoS and its five dimensions, as measured by the DSS-R, were found to be related to the behaviours associated with assertiveness. The following results can be highlighted given their magnitude. First, it was observed that the DSS-R was positively and moderately related to assertion, negatively and moderately to aggressiveness, submission, and negatively and highly to passive-aggressiveness, so greater DoS was related to more assertiveness and less aggressiveness, submission and passive-aggressiveness.

Similarly, IP was positively and moderately associated with assertion. Furthermore, ER was positively and moderately associated with aggressiveness and passive-aggressiveness. On the other hand, FO correlated positively and moderately with submission and passive-aggressiveness and negatively and moderately with assertion. Finally, DO was positively and moderately related to passive-aggressiveness and aggressiveness.

\section{Discussion}

The objective of the present study was to assess the psychometric properties of the Differentiation of Self Scale, an instrument that measures DoS in Spanish adults.

The items of the original scale were reduced by means of exploratory factor analysis, and it was found that the resulting scale, the 25-item Differentiation of Self Scale-Revised
(DSS-R), had a structure of five factors, congruent with Bowen's family systems theory: I Position, Emotional Reactivity, Fusion with Others, Emotional Cutoff, plus a dimension not yet assessed, Dominance over Others. Moreover, these factors would be subsumed in the more general factor of differentiation of self. The existence of this structure was supported by confirmatory factor analysis. First, the adequate fit of the bifactor model is evidence of the existence of a general factor and at the same time different specific factor with independent information (Chen et al., 2012). Second, the hierarchical omega, still above .70, is evidence of the existence of a general factor that is not completely explained by the multidimensionality (Reise, 2012). In addition, in bifactor models, when ECV below .70 indicates that although the general factor is important, the scale is not unidimensional and items variance is also explained by a multidimensional latent structure (Quinn, 2014). Finally, bifactor models also have the strength of revealing irrelevant dimensions, when the items loadings in a factor are not statistically significant once the general factor is controlled (Brown, 2015; Chen et al., 2006). Our results showed that, once controlled for the general factor, all items still had statistically significant loadings in the specific factor (see Table 2).

In all studies, the internal consistency indices of the revised scale and its subscales were adequate. The 5-item I Position (IP) refers to the clearly defined sense of self, setting one's own goals, the ability to distinguish one's own thoughts and feelings from the thoughts and feelings of others, and the ability to rationally adhere to one's own convictions even in stressful situations. Emotional Reactivity (ER), with 5 items, explores the tendency to respond to environmental stimuli in an uncontrolled, labile manner and with autonomous emotional responses. The 4-item Fusion with Others (FO) covers the tendency to think, feel and act like others, disregarding one's own criteria in order to avoid conflicts and disagreements and to seek approval. Dominance over Others (DO), with 5 items, is associated with the tendency to put pressure on others to conform to their own interests, to tolerate differences of opinion poorly, to enter into power struggles with others and to be dogmatic.
Table 5 Matrix of correlations of the Differentiation of Self Scale-Revised (DSS-R) with the Couple Assertion Questionnaire (CAQ)

\begin{tabular}{lllllll}
\hline & DSS-R & IP & ER & FO & DO & EC \\
\hline Assertion & $.35^{*}$ & $.28^{*}$ & -.07 & $-.33^{*}$ & $-.25^{*}$ & $-.29^{*}$ \\
Aggressiveness & $-.39^{*}$ & -.17 & $.30^{*}$ & $.19^{*}$ & $.39^{*}$ & $.21^{*}$ \\
Submission & $-.47^{*}$ & $-.22^{*}$ & $.20^{*}$ & $.49^{*}$ & $.27^{*}$ & $.38^{*}$ \\
Passive-Aggressiveness & $-.55^{*}$ & $-.24^{*}$ & $.38^{*}$ & $.38^{*}$ & $.46^{*}$ & $.31^{*}$ \\
\hline
\end{tabular}

Pearson's correlation coefficient. DSS-R Differentiation of Self Scale-Revised; IP I Position; ER Emotional Reactivity; FO Fusion with Others; $D O$ Dominance over Others; $E C$ Emotional Cutoff. Higher scores on DSS-R and its subscales indicate greater differentiation of self, I position, emotional reactivity, fusion with others, emotional cutoff, and dominance over others. Higher scores on IP and lower scores on ER, FO, DO and EC indicate a greater differentiation of self

$* p<.05$ 
Finally, Emotional Cutoff (EC), with 6 items, explores the avoidance of intimacy through physical or emotional distance from others. The IP is directly related to the construct, that is, the higher the score, the higher the degree of DoS, while the remaining subscales have an inverse relationship with the construct, so that the higher the ER, FO, DO and EC, the lower the degree of DoS.

Compared with the Spanish Differentiation of Self Inventory (S-DSI, Rodríguez-González et al., 2015), the present scale includes the dimensions I Position and Fusion with Others, two fundamental manifestations of DoS and as such, this scale incorporates all four dimensions of the Differentiation of Self Inventory-Revised (DSI-R, Skowron \& Schmitt, 2003), currently the most widely used instrument for assessing DoS. Further, unlike DSI-R and S-DSI, the DSS-R scale also incorporates a new subscale, Dominance over Others, an interpersonal manifestation of low DoS, as postulated by Bowen (Kerr \& Bowen, 1988). This subscale was highly and negatively related to DSS-R total score, that is, people with higher levels of dominance are less differentiated. Furthermore, DO was moderately and negatively related to the subscale IP, and positively related to the subscales EC, FO, and ER, that is, people with higher levels of dominance could have a less solid self and be emotionally reactive and distant or fused with others.

Regarding the evidence of convergent validity, DSS-R and the subscales IP, ER, FO, and EC were strongly related to DSI-R and its homologous subscales. Further, DO was negatively related to DSI-R total score, IP and FO, and positively to EC. It should be noted that DSI-R was recently adapted to Spanish, but only two factors (ER and EC) emerged from the factor analysis, so it means that S-DSI does not seem to assess the whole construct for Spanish population. Moreover, dominance over others is not assessed by DSI-R and the features of this dimension differ widely from fusion with others and emotional cutoff interpersonal dimensions. So, some undifferentiated people with dominant strategies are not adequately detected when they are assessed with DSI-R.

Furthermore, evidence of DSS-R's concurrent validity was observed in the predicted relations with measures of trait-anxiety and couple assertion. The results also showed that DO is positively related to trait-anxiety. Previous studies, that used the initial version of DSS, also found that DO was positively related with trait-anxiety (Duch-Ceballos et al., 2020) and attachment anxiety (Borondo \& Oliver, 2021; Oliver, 2020), characterizing DO as a non-effective strategy of relational stress control. On the other hand, DO is strongly related with aggressiveness and passive-aggressiveness in couple relationships, showing a stronger relationship with these dimensions than other DSS-R scales. DO also shows a slight relationship with submission and a negative one with assertion. People with higher levels of dominance, when struggle to tolerate different points of view in their close relationships, preferentially display aggressive strategies, but they are able to show submission strategies as an alternative, or confounding them with passive-aggressive strategies. All these results suggest that the new DO subscale appear to be a theoretically and empirically relevant component of DoS, although further research is needed concerning its relationships with other DoS dimensions and with other intrapsychic and interpersonal traits.

The present study has certain limitations, especially concerning the sampling strategy. First of all, it should be noted that the recruitment methods in all cases were convenience and snowball sampling, starting from university and professional networks, which leads to a higher homogeneity of the sample and makes it less likely that the participants were fully representative of the general population. In particular, in our sample psychologists, women, and participants with a university education are over-represented. In particular, in our sample psychologists, women, and participants with a university education are clearly over-represented. Further, although the differences were small, participants with university education had higher levels of DoS and lower levels of ER and EC than participants with no-university education. Although psychology student's overrepresentation is a common feature of psychological research (Hanel \& Vione, 2016), we acknowledge that these sampling bias can make our results mainly valid for women and highly educated populations. Additionally, we did not collect information regarding other sociodemographic variables, to fully understand the representativeness of our sample. Furthermore, because the questionnaire was online, the study excluded adults without an internet connection or those who do not use it, as well as adults less motivated to participate.

New studies should replicate the factorial analyses, test reliability and validity and calibrate the scale with more representative samples of the Spanish population to extend the results of this study. A respondent-driven sampling procedure can help to reduce biases in further research. Lastly, it is possible that different factor analysis methods could result in unique item to factor scall proliferation (e.g., number of factors), and is also a possible area of future research (Schmitt et al., 2018).

\section{Conclusion}

The Differentiation of Self Scale-Revised is a 25-item instrument that enables a complete assessment of DoS in Spanish. The scale has good psychometric properties and its brevity and ease of application facilitate its use.

The linguistic adaptation of the scale makes it possible to assess the Spanish population, and once relevant validation processes have been carried out, it could serve to 
assess the wider Spanish-speaking population. Furthermore, this instrument represents an advance in the evaluation of the construct. The scale includes five theoretical dimensions proposed by Bowen (1989), including both those of the intrapsychic axis (I Position, Emotional Reactivity) and those of the interpersonal axis including one for the first time (Fusion with Others, Emotional Cutoff, and Dominance over Others), and it promises to be highly relevant both for research and evaluation of clinical practice. The possibility of measuring dominance over others is key to understanding some undifferentiated profiles which have yet to be investigated. For example, in our study it was observed that dominance over others is related to partner aggression, so it could be a key variable in the diagnosis and prevention of intrafamily and partner violence. Furthermore, this scale may have transdiagnostic utility as it allows the assessment of elements of the psychological functioning underlying the personality disorders proposed by the Diagnostic and Statistical Manual of Mental Disorders (5th ed.; DSM-5; American Psychiatric Association, 2013), such as identity (I Position), emotional regulation (Emotional Reactivity), self-direction (Fusion with Others), tolerance of different points of view (Dominance over Others) and intimacy (Emotional Cutoff). In short, this instrument allows us to deepen our understanding of DoS, examine the functioning of adults in a more complete way, test the postulates of Bowen's family systems theory (Kerr $\&$ Bowen, 1988), and assess treatment results from a systemic and intergenerational perspective.

Supplementary Information The online version contains supplementary material available at https://doi.org/10.1007/s12144-022-02929-y.

Authors' Contributions Conceptualization: Jesús Oliver, Ana Berástegui, Elizabeth A. Skowron, Myrna L. Friedlander, Thomas A. Schmitt; Methodology: Jesús Oliver, Rafael Jódar; Formal analysis and investigation: Jesús Oliver, Rafael Jódar; Writing - original draft preparation: Jesús Oliver, Rafael Jódar, Ana Berástegui; Writing - review and editing: Jesús Oliver, Rafael Jódar, Ana Berástegui, Elizabeth A. Skowron, Myrna L. Friedlander, Thomas A. Schmitt; Resources: Jesús Oliver, Rafael Jódar, Ana Berástegui; Supervision: Jesús Oliver, Rafael Jódar, Ana Berástegui.

Funding Open Access funding provided thanks to the CRUE-CSIC agreement with Springer Nature.

Data Availability The datasets generated during and/or analysed during the current study are available at the following Open Science Framework link: https://osf.io/yauf3/?view_only=38f62a1c88de49ee9f4d $4 b 39 c 6602 a a 3$

Code Availability Not applicable.

\section{Declarations}

Ethics Approval Approval was obtained from the ethics committees of the University of Málaga and the Comillas Pontifical University. The procedures used in this study adhere to the tenets of the Declaration of Helsinki.

Consent to Participate Informed consent was obtained from all individual participants included in the study.

Consent for Publication (include appropriate statements)

Conflicts of Interest/Competing Interests On behalf of all authors, the corresponding author states that there is no conflict of interest.

Open Access This article is licensed under a Creative Commons Attribution 4.0 International License, which permits use, sharing, adaptation, distribution and reproduction in any medium or format, as long as you give appropriate credit to the original author(s) and the source, provide a link to the Creative Commons licence, and indicate if changes were made. The images or other third party material in this article are included in the article's Creative Commons licence, unless indicated otherwise in a credit line to the material. If material is not included in the article's Creative Commons licence and your intended use is not permitted by statutory regulation or exceeds the permitted use, you will need to obtain permission directly from the copyright holder. To view a copy of this licence, visit http://creativecommons.org/licenses/by/4.0/.

\section{References}

American Psychiatric Association. (2013). Diagnostic and statistical manual of mental disorders (5th ed.). American Psychiatric Association.

Bentler, P. M. (1990). Comparative fit indexes in structural models. Psychological Bulletin, 107, 238-246. https://doi.org/10.1037/ 0033-2909.107.2.238

Bentler, P. M., \& Bonett, D. G. (1980). Significance tests and goodness of fit in the analysis of covariance structures. Psychological Bulletin, 88, 588-606. https://doi.org/10.1037/0033-2909.88.3.588

Bentler, P. M., \& Chou, C. P. (1987). Practical issues in structural modeling. Sociological Methods \& Research, 16(1), 78-117.

Borondo, I., \& Oliver, J. (2021). La diferenciación del self y su relación con el apego adulto y la autoestima. Mosaico, 77, 8-18.

Bowen, M. (1989). La terapia familiar en la práctica clínica. Vols. 1 y 2. Desclée de Brouwer.

Bray, J. H., Williamson, D. S. \& Malone, P. E. (1984). Personal authority in the family system: Development of a questionnaire to measure personal authority in intergenerational family processes. Journal of Marital \& Family Therapy, 10, 167-178. https://doi.org/10. 1111/j.1752-0606.1984.tb00007.x

Brown, T. A. (2015). Confirmatory factor analysis for applied research. The Guilford Press.

Carrasco, M. (1996). Cuestionario de Aserción en la pareja. TEA.

Cavaiola, A. A., Peters, C., Hamdan, N., \& Lavender, N. J. (2012). Differentiation of self and its relation to work stress and work satisfaction. Journal of Psychological Issues in Organizational Culture, 3(1), 7-20. https://doi.org/10.1002/jpoc.20092

Chen, F. F., West, S. G., \& Sousa, K. H. (2006). A comparison of bifactor and second-order models of quality of life. Multivariate Behavioral Research, 41(2), 189-225.

Chen, F. F., Hayes, A., Carver, C. S., Laurenceau, J. P., \& Zhang, Z. (2012). Modeling general and specific variance in multifaceted constructs: A comparison of the bifactor model to other approaches. Journal of Personality, 80(1), 219-251.

Dolz-del-Castellar, B., \& Oliver, J. (2021). Relationship between family functioning, differentiation of self and anxiety in Spanish 
young adults. PLoS One, 16(3), 1-16. https://doi.org/10.1371/ journal.pone. 0246875

Duch-Ceballos, C., Oliver, J., \& Skowron, E. (2020). Differentiation of self and its relationship with emotional self-regulation and anxiety in a Spanish sample. The American Journal of Family Therapy. https://doi.org/10.1080/01926187.2020.1841039

Dueber, D. (2021). Package 'BifactorIndicesCalculator'. R package version 0.2.2. https://cran.r-project.org/web/packages/BifactorIn dicesCalculator/BifactorIndicesCalculator.pdf.

Freeman, H., \& Almond, T. (2009). Predicting adolescent self differentiation from relationships with parents and romantic partners. International Journal of Adolescence and Youth, 15, 121-143. https://doi.org/10.1080/02673843.2009.9748023

Haber, J. (1984). An investigation of he relationship between differentiation of self, complementary psychological need patterns and marital conflict (Doctoral dissertation, New York University). Dissertation Abstracts International, 45, 2102B.

Hanel, P. H., \& Vione, K. C. (2016). Do student samples provide an accurate estimate of the general public? PLoS One, 11(12), $\mathrm{e} 0168354$.

Isik, E., \& Bulduk, S. (2015). Psychometric properties of the differentiation of self inventory-revised in Turkish adults. Journal of Marital and Family Therapy, 41(1), 102-112. https://doi.org/10. 1111/jmft.12022

Jankowski, P. J., \& Hooper, L. M. (2012). Differentiation of self: A validation study of the Bowen theory construct. Couple and Family Psychology: Research and Practice, 1(3), 226-243. https://doi. org/10.1037/a0027469

Jankowski, P. J., Hooper, L. M., Sandage, S. J., \& Hannah, N. J. (2013). Parentification and mental health symptoms: Mediator effects of perceived unfairness and differentiation of self. Journal of Family Therapy, 35(1), 43-65. https://doi.org/10.1111/j.1467-6427. 2011.00574.x

Kerr, M. E., \& Bowen, M. (1988). Family evaluation. Norton.

Kim, H., Prouty, A. M., Smith, D. B., Ko, M., Wetchler, J. I., \& Oh, J. (2015). Differentiation and healthy family functioning of Koreans in South Korea, south Koreans in the United States, and white Americans. Journal of Marital and Family Therapy, 41(1), 72-85. https://doi.org/10.1111/jmft.12049

Lam, C. M., \& Chan-So, P. C. Y. (2015). Validation of the Chinese version of differentiation of self inventory (C-DSI). Journal of Marital and Family Therapy, 41(1), 86-101. https://doi.org/10. $1111 /$ jmft.12031

Lampis, J., Busonera, A., Cataudella, S., Tomassi, M., \& Skowron, E. A. (2017). Psychometric properties of an Italian version of the differentiation of self inventory-revised (it-DSI-R). Journal of Adult Development, 24, 144-154. https://doi.org/10.1007/ s10804-016-9253-6

Lampis, J., Cataudella, S., Agus, M., Busonera, A., \& Skowron, E. A. (2019). Differentiation of self and dyadic adjustment in couple relationships: A dyadic analysis using the actor-partner interdependence model. Family Process, 58(3), 698-715. https://doi.org/ $10.1111 /$ famp. 12370

Licht, C., \& Chabot, D. (2006). The Chabot emotional differentiation scale: A theoretically and psychometrically sound instrument for measuring Bowen's intrapsychic aspect of differentiation. Journal of Marital and Family Therapy, 32(2), 167-180. https://doi.org/ 10.1111/j.1752-0606.2006.tb01598.x

Major, S., Miranda, C., Rodríguez-González, M., \& Relvas, A. P. (2014). Adaptação Portuguesa do differentiation of self inventoryrevised (DSI-R): Um estudo exploratório. Revista Iberoamerica de Diagnóstico y Evaluación Psicológica, 37(1), 99-123.

Maß, R., Schottke, M.-L., Borchert, A.-M., Ellermann, P. M., Jahn, L. M., \& Morgenroth, O. (2019). Die deutsche version des differentiation of self inventory (DSI-G). Zeitschrift für Klinische
Psychologie und Psychotherapie, 48(1), 17-28. https://doi.org/ 10.1026/1616-3443/a000495

Miller, R. R., Anderson, S., \& Keala, D. K. (2004). Is Bowen theory valid? A review of basic research. Journal of Marital and Family Therapy, 30(4), 453-466. https://doi.org/10.1111/j.1752-0606. 2004.tb01255.x

Muthén, L. K., \& Muthén, B. O. (1998-2017). Mplus User's Guide. Eighth Edition. Muthén \& Muthén.

Neophytou, K., Schweer-Collins, M. L., Rodríguez-González, M., Jódar, R., \& Skowron, E. A. (2020). The differentiation of self inventory - Revised: A validation study in the Greek cultural context. The American Journal of Family Therapy. https://doi.org/10. 1080/01926187.2020.1783388

Nunally, J. C. (1978). Psychometric theory. McGraw-Hill.

Oliver, J. (2020). Variables familiares relacionadas con la diferenciación del self y el apego de las personas adultas adoptadas (doctoral dissertation, Universidad Pontificia Comillas). https:// repositorio.comillas.edu/xmlui/bitstream/handle/11531/45373/ TD00385.pdf? sequence $=1 \&$ isAllowed $=\mathrm{y}$

Oliver, J., \& Berástegui, A. (2019). La Escala de Diferenciación del Self (EDS): desarrollo y validación inicial. Revista Mosaico, 72, 100-119. https://www.repositorio.comillas.edu/xmlui/handle/ $11531 / 36773$

Oliver, J., Fábregas, I., Lerín, M. C., \& Nieves, Y. (2012). PIUMAD: Un programa para la prevención de adicciones en Universidades de Madrid. Instituto de Adicciones de Madrid Salud.

Peiró, C., Oliver, J., \& Candelas, I. (2015). Redes familiares para la prevención. Manual de formación 2015. CONCAPA. http:// www.concapa.org/content/ uploads/2015/ 11/Guia-padres-2015. pdf.

Quinn, H. O. C. (2014). Bifactor models, explained common variance (ECV), and the usefulness of scores from unidimensional item response theory analyses. [thesis for the degree of master of arts, University of North Carolina at Chapel Hill]. Carolina digital repository. https://cdr.lib.unc.edu/concern/dissertations/ w95051780.

R Core Team (2020). R: A language and environment for statistical computing. $\mathrm{R}$ Foundation for statistical computing. https:// www.r-project.org/.

Reise, S. P. (2012). The rediscovery of bifactor measurement models. Multivariate Behavioral Research, 47(5), 667-696.

Revelle, W. (2019). Psych: Procedures for psychological, psychometric, and personality research. $\mathrm{R}$ package version, 1(10). https:// www.personality-project.org/r/psych-manual.pdf.

Rodrigues, A. (2016). Exploring the relationships among attachment, emotion regulation, differentiation of self, negative problem orientation, self-esteem, worry and generalized anxiety (doctoral dissertation, University of Toronto). https://search. proquest.com/docview/1821617854?accountid=14568.

Rodríguez, M., \& Kerr, M. (2011). Introducción a las aplicaciones de la teoría familiar sistémica de Murray Bowen a la terapia familiar y de pareja. Cuadernos de Terapia Familiar, 77, 7-15.

Rodriguez, A., Reise, S. P., \& Haviland, M. G. (2016). Evaluating bifactor models: Calculating and interpreting statistical indices. Psychological Methods, 21(2), 137.

Rodríguez-González, M., \& Martínez, M. (2015). La teoría familiar sistémica de Bowen: avances y aplicación terapéutica. McGraw Hill.

Rodríguez-González, M., Skowron, E., \& Jódar, R. (2015). Spanish adaptation of the differentiation of self inventory-revised (DSI-R). Terapia Psicológica, 33(1), 47-58.

Rodríguez-González, M., Schweer-Collins, M., Skowron, E. A., Jódar, R., Cagigal, V., \& Major, S. O. (2018). Stressful life events and physical and psychological health: Mediating effects of differentiation of self in a Spanish sample. Journal of Marital and Family Therapy. https://doi.org/10.1111/jmft.12358 
Rodríguez-González, M., Lampis, J., Murdock, N. L., Schweer-Collins, M. L., \& Lyons, E. R. (2020). Couple adjustment and differentiation of self in the United States, Italy, and Spain: A cross-cultural study. Family Process. https://doi.org/10.1111/famp.12522

Sandage, S. J., \& Jankowski, P. J. (2010). Forgiveness, spiritual instability, mental health symptoms, and well-being: Mediator effects of differentiation of self. Psychology of Religion and Spirituality, 2(3), 168-180. https://doi.org/10.1037/a0019124

Sass, D. A., \& Schmitt, T. A. (2010). A comparative investigation of rotation criteria within exploratory factor analysis. Multivariate Behavioral Research, 45(1), 73-103. https://doi.org/10.1080/ 00273170903504810

Schmitt, T. A. (2011). Current methodological considerations in exploratory and confirmatory factor analysis. Journal of Psychoeducational Assessment, 29(4), 304-321. https://doi.org/10.1177/ 0734282911406653

Schmitt, T. A., \& Sass, D. A. (2011). Rotation criteria and hypothesis testing for exploratory factor analysis: Implications for factor pattern loadings and Interfactor correlations. Educational and Psychological Measurement, 71(1), 95-113. https://doi.org/10.1177/ 0013164410387348

Schmitt, T. A., Sass, D. A., Chappelle, W., \& Thompson, W. (2018). Selecting the "best" factor structure and moving measurement validation forward: An illustration. Journal of Personality Assessment, 100(4), 345-362. https://doi.org/10.1080/00223891.2018. 1449116

Seisdedos, N. (1986). STAI, Manual for the State-Trait Anxiety Inventory (Self Evaluation Questionnaire). TEA Ediciones.

Skowron, E. A. (2000). The role of differentiation of self in marital adjustment. Journal of Counseling Psychology, 47, 229-237. https://doi.org/10.1037/0022-0167.47.2.229
Skowron, E. A., \& Friedlander, M. L. (1998). The differentiation of self inventory: Development and initial validation. Journal of Counseling Psychology, 45(3), 235-246. https://doi.org/10.1037/ 0022-0167.45.3.235

Skowron, E. A., \& Schmitt, T. A. (2003). Assessing interpersonal fusion: Reliability and validity of a new DSI fusion with others. Journal of Marital and Family Therapy, 29(2), 209-222. https:// doi.org/10.1111/j.1752-0606.2003.tb01201.x

Skowron, E. A., Stanley, K., \& Shapiro, M. (2009). A longitudinal perspective on differentiation of self, interpersonal, and psychological well-being in young adulthood. Contemporary Family Therapy, 31, 3-18. https://doi.org/10.1007/s10591-008-9075-1

Spielberger, C. D., Gorsuch, R. L., \& Lushene, R. E. (1970). STAI manual for the state-trait anxiety inventory. Consulting Psychologist Press.

Tang, W., Cui, Y., \& Babenko, O. (2014). Internal consistency: Do we really know what it is and how to assess it? Journal of Psychology and Behavioral Science, 2(2), 205-220.

The Bowen Center. (2021). Bowen theory. The eight concepts of Bowen Theory. Differentiation of self. https://www.thebowence nter.org/differentiation-of-self.

Thorndike, R. L. (1982). Applied psychometrics. Houghton-Mifflin.

Willis, B. T., \& Cashwell, C. S. (2017). Predicting identity status: The role of attachment, differentiation, and meaning making. Adultspan Journal, 16(2), 80-92. https://doi.org/10.1002/adsp.12037

Publisher's Note Springer Nature remains neutral with regard to jurisdictional claims in published maps and institutional affiliations. 